\section{THU0125 CARDIOVASCULAR DISEASE RISK FACTORS MAY NEGATIVELY IMPACT RHEUMATOID ARTHRITIS DISEASE OUTCOMES: FINDINGS FROM THE ONTARIO BEST PRACTICES RESEARCH INITIATIVE}

Kangping Cui ${ }^{1}, 2$, Mohammad Movahedi ${ }^{2}$, Claire Bombardier ${ }^{2,3}$, Bindee Kuriya ${ }^{2,4}$. ${ }^{1}$ Western University, Internal Medicine, London, Canada; ${ }^{2}$ University Health Network, Toronto General Hospital Research Institute, Toronto, Canada: ${ }^{3}$ University of Toronto, Department of Medicine and Institute for Health Policy, Management and Evaluation, Toronto, Canada; ${ }^{4}$ Mount Sinai Hospital, Rheumatology, Toronto, Canada

Background: Rheumatoid arthritis increases the risk of cardiovascular disease (CVD). Less is known about the direct influence of CVD and CVD risk factors (RF) on RA outcomes, but higher comorbidity burden has been suggested to adversely affect RA treatment response ${ }^{1-2}$.

Objectives: We tested our hypothesis that CVD risk factors (RFs) alone, in the absence of CVD, are associated with higher disease activity and disability in RA.

Methods: The Ontario Best Practices Research Initiative (OBRI) is a clinical registry of RA patients followed in routine care. RA subjects with complete data to calculate disease activity according to the Disease Activity Score-28 (DAS28), Clinical Disease Activity Index (CDAl), 28 swollen joint count (SJC28) and functional status (Health Assessment Questionnaire Disability Index [HAQ-DI]) at cohort entry were selected. Patients were divided into mutually exclusive groups by baseline CVD status as: (1) no CVD/no CVD RFs; (2) CVD including coronary artery disease, myocardial infarction, cerebral vascular accidents, and peripheral arterial disease; (3) no CVD but CVD RFs including hypertension (HTN), dyslipidemia (DLD), diabetes (DM), or smoking. We performed separate linear regression analyses for each outcome, adjusted for baseline clinical and demographic variables, to determine the independent effect of CVD status on disease outcomes at baseline and one year follow-up.

Results: Of 2033 patients examined, $49.5 \%$ had no CVD, 5.4\% had CVD and $45.1 \%$ had CVD RFs alone. The most common RF was HTN $(33 \%)$ followed by DLD (19.7\%), current smoking (17\%), and DM (8.1\%). At cohort entry, having a CVD RF was associated with significantly higher DAS28 $(\beta \quad 0.13,95 \% \mathrm{Cl} 0.002-0.26, p 0.04)$ and HAQ-DI $(\beta \quad 0.16,95 \% \mathrm{Cl}$ $0.10-0.23, \mathrm{p}<0.0001)$. At one year, CVD RF was associated with worse DAS28 $(\beta \quad 0.17,95 \% \mathrm{Cl} 0.05-0.30, p 0.01)$ and $\mathrm{CDAl}(\beta \quad 0.96,95 \% \mathrm{Cl}$ $0.05-1.87, p 0.04$ ) but not HAQ-DI ( $\beta 0.03,95 \% \mathrm{Cl}-0.002-0.08$, p 0.17 ). Having higher number of CVD RF was associated with worse disease outcomes. No association between CVD status and swollen joint count was observed.

Conclusion: Even in the absence of CVD, traditional CVD RF are associated with greater RA disease severity and disability both at baseline and one year. Self-perceived impact of comorbidity (patient global assessment of health) may be driving this relationship. Moreover, patients with CVD RF maybe more treatment-resistant, suggesting that co-management of CVD RF in RA patients may be beneficial on both fronts.

\section{REFERENCES:}

[1] Avina-Zubieta, J. A., Thomas, J., Sadatsafavi, M., Lehman, A. J. \& Lacaille, D. Risk of incident cardiovascular events in patients with rheumatoid arthritis: a meta-analysis of observational studies. Ann. Rheum. Dis. 71, 1524-1529 (2012)

[2] Crepaldi, G. et al. Cardiovascular Comorbidities Relate More than Others with Disease Activity in Rheumatoid Arthritis. PLoS One 11, (2016).

Abstract THU0125 Table 1. Multivariable linear regression of disease activity outcomes and functional status at one-year according to CVD status.

\begin{tabular}{|c|c|c|c|c|}
\hline & \multicolumn{4}{|c|}{$\beta$ - coefficient $(95 \% \mathrm{Cl}) ; p$-value } \\
\hline & DAS28-ESR & CDAI & SJC-28 & HAQ-DI \\
\hline CVD status & $\mathrm{N}=1965$ & $\mathrm{~N}=1965$ & $\mathrm{~N}=1965$ & $\mathrm{~N}=1965$ \\
\hline No CVD/No & Ref & Ref & Ref & Ref \\
\hline CVD RFs & & & & \\
\hline CVD & $\begin{array}{c}0.12(- \\
0.14,0.38), 0.37\end{array}$ & $\begin{array}{c}0.50(- \\
1.45,2.46), 0.61\end{array}$ & $\begin{array}{c}0.44(- \\
0.21,1.10), 0.19\end{array}$ & $\begin{array}{c}0.09(- \\
0.02,0.19), 0.10\end{array}$ \\
\hline $\begin{array}{l}\text { CVD RFs/No } \\
\text { CVD }\end{array}$ & $\begin{array}{c}0.17(0.05,0.30) \\
0.01\end{array}$ & $\begin{array}{c}0.96(0.05,1.87) \\
0.04\end{array}$ & $\begin{array}{c}0.29(- \\
0.01,0.60), 0.06\end{array}$ & $\begin{array}{c}0.03(- \\
0.02,0.08), 0.17\end{array}$ \\
\hline
\end{tabular}

\section{Acknowledgement: OBRI investigators}

Disclosure of Interests: Kangping Cui: None declared, Mohammad Movahedi Employee of: ONTARIO BEST PRACTICE RESEARCH INITIATIVE (OBRI), Claire Bombardier Grant/research support from: Abbvie, Amgen, Bristol-Myers Squibb, Celgene, Eli Lilly, Hospira, Janssen, Merck, Novartis, Pfizer Inc, Roche, Sanofi, UCB, Consultant for: AbbVie, Hospira, Janssen, Merck, Novartis, Pfizer Inc, Sanofi, Speakers bureau: Roche, Bindee
Kuriya Consultant for: Advisory Board Member: Abbvie, Sanofi Genzyme, Eli Lilly, Pfizer Canada, Roche DOI: 10.1136/annrheumdis-2019-eular.2484

\section{THU0126 FACTORS AFFECTING THE DISCREPANCY BETWEEN PATIENT AND PHYSICIAN GLOBAL ASSESSMENT OF DISEASE ACTIVITY IN PATIENTS WITH EARLY RHEUMATOID ARTHRITIS OVER TIME}

Pooneh Akhavan ${ }^{1}$, Mohammad Movahedi ${ }^{2}$, Claire Bombardier ${ }^{1,2}$. ${ }^{1}$ University of Toronto, Mount Sinia Hospital, Rheumatology, Toronto, Canada; ${ }^{2}$ Toronto General Research Institute, University Health Network, Ontario Best Practices Initiatives, Toronto, Canada

Background: Rheumatoid Arthritis (RA) is a chronic disease that requires regular follow-ups over time. Physicians make treatment adjustments based on their evaluation of disease status and patients' response to treatment while patients' perception of disease activity may change over time.

Objectives: we aimed to assess the discrepancy between patient global assessment of disease activity and physician assessment of disease activity at baseline and after one year in patients with early RA. We also evaluated factors affecting this discrepancy at these two time points. Methods: Patients enrolled in the Ontario Best Practices Research Initiative (OBRI), a prospective observational cohort of patients with RA who had disease duration of $<12$ months (early RA) and had visits both at baseline and after one year were included. The discrepancy between patient global assessment of disease activity (PTGA) and physician global assessment of disease activity (MDGA) was calculated by simple subtraction (PTGA-MDGA). The value of $\geq 30$ was considered discordant which could be either positive or negative in favor of PTGA or MDGA. Linear regression analysis was used to assess factors affecting PTGA, MDGA and PTGA-MDGA discrepancy at baseline and one year.

Results: A total of 460 patients with early RA were analyzed. Majority were female $(72.4 \%)$ with mean $( \pm S D)$ age of 57 years $( \pm 0.6)$. the dis cordance rate was $109(24 \%)$ and $99(21 \%)$ at baseline and one year, respectively. In the majority of the discordant cases, PTGA was higher (98 $(90 \%)$ at baseline and $85(86 \%)$ at one year). Discordant patients had significantly higher fatigue score, health assessment questionnaire disability index (HAQ-DI), pain score, PTGA, MDGA, tender join, composite measures of disease activity and higher number of comorbidities at baseline.

Multivariable regression analysis showed that the higher PTGA is significantly associated with higher SJC, TJC and fatigue both at baseline and one year and with higher pain score only at one year. Similar associations were found for MDGA except fatigue which was not significant. Multivariable regression analysis showed that the higher discrepancy between PTGA and MDGA is associated significantly with lower SJC $(\beta=-2.75)$, higher TJC $(\beta=1.17)$, and higher fatigue $(\beta=0.85)$ at baseline. At one-yea follow-up, higher pain was the strongest factor $(\beta=4.99)$ for affecting the higher PTGA-MDGA discrepancy compared with SJC $(\beta=-1.65)$ and fatigue $(\beta=1.24)$

Conclusion: Significant discrepancy between PTGA and MDGA exists in about a quarter of patients with early RA at baseline and slightly less after one year. In the majority of these patients PTGA is higher over time. The number of active joints affects both assessments and this effect persists at one year. Clinicians should consider the above associations when makin

Acknowledgement: OBRI-RA Investigators: Drs. Ahluwalia, V., Ahmad, Z., Akhavan, P., Albert, L., Alderdice, C., Aubrey, M., Aydin, S., Bajaj, S. Bensen, B., Bhavsar, S., Bobba, R., Bombardier, C., Bookman, A., Cabral, A., Carette, S., Carmona, R., Chow, A., Ciaschini, P., Cividino, A., Cohen, D., Dixit, S., Haaland, D., Hanna, B., Haroon, N., Hochman, J., Jaroszynska, A., Johnson, S., Joshi, R., Kagal, A., Karasik, A., Karsh, J., Keystone, E., Khalidi, N., Kuriya, B., Larche, M., Lau, A., LeRiche, N., Leung, Fe., Leung, Fr., Mahendira, D., Matsos, M., McDonald-Blumer, Midzic, I., Milman, N., H., Mittoo, S., Mody, A., Montgomery, A., Mulgund M., Ng, E., Papneja, T., Pavlova, P., Perlin, L., Pope, J, Purvis, J., Rohekar, G., Rohekar, Ruban, T., S., Samadi, N., Shaikh, S., Shickh, A. Shupak, R., Smith, D., Soucy, E., Stein, J., Thompson, A., Thorne, C. Wilkinson, S.g treatment decisions.

Disclosure of Interests: Pooneh Akhavan: None declared, Mohammad Movahedi: None declared, Claire Bombardier Grant/research support from: Abbvie, Amgen, Bristol-Myers Squibb, Celgene, Eli Lilly, Hospira, Janssen, Merck, Novartis, Pfizer Inc, Roche, Sanofi, UCB, Consultant for: AbbVie, Hospira, Janssen, Merck, Novartis, Pfizer Inc, Sanofi, Speakers bureau: Roche 